\title{
Central Precocious Puberty in a Boy with Pseudohypoparathyroidism Type 1A due to a Novel GNAS Variant, with Congenital Hypothyroidism as the First Manifestation
}

\author{
(D) Somboon Wankanit, (D) Pat Mahachoklertwattana, (D) Thipwimol Tim-Aroon, (D) Kinnaree Sorapipatcharoen, \\ (D) Preamrudee Poomthavorn
}

Department of Pediatrics, Faculty of Medicine Ramathibodi Hospital, Mahidol University, Bangkok, Thailand

\begin{abstract}
What is already known on this topic?
Resistance to multiple hormones as evidenced by pseudohypoparathyroidism, hypothyroidism and hypogonadism is characteristics of pseudohypoparathyroidism type 1A (PHP1A). Mild congenital hypothyroidism may manifest as the first and only clinical presentation of patients with PHP1A.
\end{abstract}

What this study adds?

Boys with PHP1A might develop central precocious puberty, despite having multiple hormone resistance.

\begin{abstract}
Pseudohypoparathyroidism (PHP) type 1A (PHP1A) is a disorder of multiple hormone resistance, mainly parathyroid hormone. It is associated with Albright hereditary osteodystrophy phenotypes. Patients with PHP1A may initially present with hypothyroidism during infancy and later develop typical PHP1A characteristics during their childhood. Central precocious puberty (CPP) is extremely rare among PHP1A patients in whom gonadotropin resistance is more usual. This is a case report of a 9.5-year-old boy with congenital hypothyroidism who developed hypocalcemia secondary to PHP. He had relatively short stature with height standard deviation score of -0.9. Obesity had been noted since the age of two years. At the presentation of PHP, pubertal-sized testes of $10 \mathrm{~mL}$ were observed, and CPP was documented with serum testosterone concentration of $298 \mathrm{ng} / \mathrm{dL}$ (normal for Tanner stage III, 100-320), luteinizing hormone of $3.9 \mathrm{IU} / \mathrm{L}$ (normal, 0.2-5.0), and follicle stimulating hormone of $4.8 \mathrm{IU} / \mathrm{L}$ (normal, 1.2-5.8). Pituitary magnetic resonance imaging was unremarkable. Genetic analysis confirmed the diagnosis of PHP1A with a novel heterozygous missense variant of GNAS gene in exon 13 , c.1103A > G (p.Asp368Gly). Awareness of PHP1A diagnosis in patients with congenital hypothyroidism and early childhood-onset obesity is important for early diagnosis. Apart from multiple hormone resistance, CPP may manifest in patients with PHP1A.
\end{abstract}

Keywords: Pseudohypoparathyroidism, precocious puberty, hypothyroidism

\section{Introduction}

Pseudohypoparathyroidism (PHP) type 1A (PHP1A) is a disorder of multiple hormone resistance in which a decreased responsiveness to parathyroid hormone (PTH), leading to hypocalcemia and hyperphosphatemia, is a main defect (1). It is caused by heterozygous loss-offunction variants in the coding sequence of GNAS gene that cause defects in the $\alpha$-subunit of the stimulatory $G$ protein (Gs $\alpha$ ) (2). Resistance to other hormones, which includes thyroid stimulating hormone (TSH), gonadotropins and growth hormone (GH)-releasing hormone, causes hypothyroidism, hypogonadism and GH deficiency, respectively (2). In addition, PHP1A is associated with Albright hereditary osteodystrophy (AHO) phenotypes, including short stature, brachydactyly, obesity, round face, and ectopic ossifications $(1,2)$. TSH resistance has frequently been described as the presenting feature of PHP1A with diverse severity, from isolated hyperthyrotropinemia to overt hypothyroidism, 
and might present at birth as congenital hypothyroidism or later during infancy and childhood $(2,3)$. The diagnosis of PHP1A was reported to often be delayed in patients presenting with isolated TSH resistance, until other manifestations became apparent $(4,5,6,7)$.

Some PHP1A patients also demonstrate elevated gonadotropin levels which represents gonadotropin resistance $(8,9,10,11,12)$. This finding was mainly reported in female PHP1A patients who presented with either amenorrhea or oligomenorrhea $(9,10,11)$. In contrast, male PHP1A patients were rarely reported to have gonadotropin resistance $(10,11,12)$.

Central precocious puberty (CPP), a condition which is the biological opposite of gonadotropin resistance, is unlikely to be present in PHP1A patients. However, there are at least two reports of CPP in two PHP boys who had PTH as the only hormone resistance $(13,14)$. Herein, we report another boy with PHP1A who was diagnosed with isolated hyperthyrotropinemia during infancy, and developed symptomatic hypocalcemia secondary to PHP1A later in his childhood, at which time CPP was also diagnosed.

\section{Case Report}

A 9.5-year-old boy who had been diagnosed as having mild congenital hypothyroidism since the age of 11 months presented to our hospital for the first time with viral infection and tetany. Physical examination revealed body temperature of $38.8^{\circ} \mathrm{C}$, heart rate of 82 beats per minute, blood pressure of $97 / 61 \mathrm{mmHg}$, height of 128 $\mathrm{cm}$ [-0.9 standard deviation score (SDS)], weight of $38 \mathrm{~kg}$ $(+1.8 \mathrm{SDS})$ and body mass index of $23.2 \mathrm{~kg} / \mathrm{m}^{2}(+2.6$ SDS). Carpopedal spasm and positive Chvostek's sign were noted. He had a round face and short fourth and fifth metacarpal bones. No subcutaneous calcification was observed. Chest, abdominal and neurological examinations were unremarkable. Investigations for his tetany revealed a finding which was consistent with PTH resistance or PHP, including hypocalcemia, hyperphosphatemia and elevated intact PTH level concomitant with hypocalciuria and high tubular reabsorption of phosphate (Table 1). His clinical presentations including AHO phenotype (obesity, round face, short metacarpal bones and relatively short stature) and PHP led to the provisional diagnosis of PHP1A. Supportive treatment for viral infection was administered. Hypocalcemia secondary to PHP was initially treated with

Table 1. Clinical characteristics of the reported patient and previous reports of boys with pseudohypoparathyroidism (PHP) who had central precocious puberty at the diagnosis of PHP

\begin{tabular}{|c|c|c|c|}
\hline Characteristics & This report & Kagami et al. (13) & Rossodivita et al. (14) \\
\hline Age at diagnosis, years & 9.5 & 10.0 & 11.5 \\
\hline Height, cm (SDS) & $128(-0.9)$ & $138(+0.2)$ & $157(+1.9)$ \\
\hline Predicted adult height, cm (SDS) & $151(-3.5)$ & $162(-2.0)$ & $179(+0.3)$ \\
\hline Weight, kg (SDS) & $38(+1.8)$ & $39(+0.7)$ & $46(+1.2)$ \\
\hline Body mass index, $\mathrm{kg} / \mathrm{m}^{2}$ (SDS) & $23.2(+2.6)$ & $20.2(+1.6)$ & $18.9(+0.7)$ \\
\hline Bone age, years & 13.0 & 13.0 & 13.5 \\
\hline Testicular volume, $\mathrm{mL}$ & 10 & $6-8$ & $12-15$ \\
\hline Serum calcium, mg/dL & 6.0 & 5.3 & 4.2 \\
\hline Serum phosphorus, mg/dL & 8.3 & 11.1 & 10.3 \\
\hline Serum magnesium, mg/dL & 1.7 & NA & 1.5 \\
\hline Serum intact PTH, pg/mL & 137 & 363 & 191 \\
\hline Serum 25-hydroxyvitamin D, ng/mL & 35 & 16 & 20 \\
\hline Serum testosterone, ng/dL & 298 & 250 & 384 \\
\hline Serum LH, IU/L & 3.9 (random) & 18.0 (GnRH-stimulated) & 2.8 (random), 29.9 (GnRH-stimulated) \\
\hline Serum FSH, IU/L & 4.8 (random) & 7.0 (GnRH-stimulated) & 6.9 (random), 13.3 (GnRH-stimulated) \\
\hline Urine calcium & $\begin{array}{l}0.01 \mathrm{mg} / \mathrm{mg} \text { of creatinine }(\mathrm{N}, 0.03 \text { - } \\
0.26)\end{array}$ & NA & 4.9 mg/kg/day (N, 0.8-2.8) \\
\hline Tubular reabsorption of phosphate, $\%$ & 97.6 & NA & 95.0 \\
\hline GNAS variant & c.1103A > G; p.Asp368Gly & $\begin{array}{l}\text { c.568dupT; } \\
\text { p.Tyr 190Leufs } * 20\end{array}$ & NA \\
\hline \multicolumn{4}{|c|}{$\begin{array}{l}\text { Normal range: serum calcium 8.7-10.7 mg/dL, phosphorus } 3.3-5.4 \mathrm{mg} / \mathrm{dL} \text {, magnesium 1.6-2.4 mg/dL, intact PTH 10-65 pg/mL, 25-hydroxyvitamin D } 30-100 \mathrm{ng} / \mathrm{mL} \text {, } \\
\text { testosterone (Tanner stage III) 100-320 ng/dL, tubular reabsorption of phosphate } 90-95 \% \text {. } \\
\text { FSH: follicle-stimulating hormone, GnRH: gonadotropin-releasing hormone, LH: luteinizing hormone, N: normal, NA: not available, PTH: parathyroid hormone, SDS: } \\
\text { standard deviation score }\end{array}$} \\
\hline
\end{tabular}


intravenous calcium gluconate concomitant with oral calcium carbonate and calcitriol. Tetany resolved following intravenous calcium gluconate treatment and normalization of serum calcium and phosphorus concentrations was gradually achieved with oral calcium carbonate and calcitriol.

Regarding his past medical and congenital hypothyroidism history, he was born at 35 weeks of gestation with a birth weight of $2.6 \mathrm{~kg}(+0.1 \mathrm{SDS})$ and length of $47 \mathrm{~cm}(+0.4$ SDS). His developmental milestones were normal. He had a positive serum TSH screening level of $29 \mathrm{mU} / \mathrm{L}$ (normal, $<25$ ). Subsequent thyroid functions at ages 11 days to 7 months showed serum TSH levels of 5.6-12.1 mU/L (normal, 0.7-4.2) and free thyroxine (T4) levels of 1.1-1.2 ng/dL (normal, 0.9-1.7), indicating isolated hyperthyrotropinemia. Levothyroxine was not started until the age of 11 months when his TSH level rose to $16.2 \mathrm{mU} / \mathrm{L}$ with normal free T4 of $0.9 \mathrm{ng} / \mathrm{dL}$. Free T4 and TSH normalized within four weeks following levothyroxine treatment. Taken together, congenital hypothyroidism or TSH resistance, one of the PHP1A phenotypes, was the first manifestation of PHP in this patient.

His growth trajectory had been tracking along the $75^{\text {th }}$ percentile for weight and the $3^{\text {rd }}$ percentile for height since he was 2 years of age. His mid-parental height was 159 $\mathrm{cm}(-2.0 \mathrm{SDS})$. His height velocity had strikingly increased by $9.5 \mathrm{~cm}$ during the past year. Pubertal assessment demonstrated testicular size of $10 \mathrm{~mL}$, penile length of 7 $\mathrm{cm}$ and Tanner stage III pubic hair. Based on his height velocity and secondary sex characteristics, pubertal onset had presumably begun before 9 years of age. Therefore, the findings were consistent with gonadotropin-dependent precocious puberty or CPP. The diagnosis was confirmed by the findings of pubertal levels of serum testosterone, luteinizing hormone and follicle-stimulating hormone (FSH), and advanced bone age (Table 1). Pituitary magnetic resonance imaging was normal. He was commenced on depot gonadotropin-releasing hormone analog to preserve final adult height.

A novel heterozygous missense variant of the GNAS gene (NM_000516.5) in exon 13, c.1103A > G (p.Asp368Gly) was identified in the patient. The variant was classified as likely pathogenic based on the American College of Medical Genetics criteria (15). The variant has not been reported in individuals with PHP1A or in the gnomAD, ExAC and in-house Thai Exome databases. Multiple computer prediction algorithms including SIFT, DANN, PrimateAI REVEL, MutationTaster, MVP, Polyphen2HVAR, BayesDel_addAF, DEOGEN2, EIGEN, FATHMM-MKL, LIST-S2, M-CAP, and MutationAssessor classified the variant as damaging or deleterious. The sequence data has been submitted to the GenBank database under accession number MW503931.

Maternally-inherited heterozygous inactivating GNAS mutation is usually the cause of PHP1A. His mother's height was $140 \mathrm{~cm}(-3.6 \mathrm{SDS})$ and she had short fourth and fifth metacarpal bones. Her serum calcium, phosphorus and intact PTH levels were normal at $9.2 \mathrm{mg} / \mathrm{dL}$ (normal, 8.5-10.5), $3.2 \mathrm{mg} / \mathrm{dL}$ (normal, 2.4-4.4) and $54 \mathrm{pg} / \mathrm{mL}$ (normal, 10-65), respectively. Since AHO phenotype was observed in the absence of PTH resistance, the diagnosis of pseudopseudohypoparathyroidism was likely in his mother. Genetic testing revealed the same variant in GNAS gene as found in the patient.

The report was approved by the Ethics Committee of the Faculty of Medicine Ramathibodi Hospital, Mahidol University (date: 23.02.2021, MURA 2021/161) and conformed to the Declaration of Helsinki.

Informed assent and consent were obtained from the patient and his parents, respectively.

\section{Discussion}

The patient in this report had mild congenital hypothyroidism without documented AHO phenotypes (such as finger abnormalities) during the early life, as the first manifestation of PHP1A. In fact, hyperthyrotropinemia representing TSH resistance, is a common finding and could be the earliest hormonal dysfunction in PHP1A patients, because elevated TSH concentration might be detected at the time of neonatal screening $(2,3,4,5)$. Unlike resistance to TSH, PTH resistance, the hallmark of PHP1A, usually manifests after the first few years of life due to gradual silencing of paternal Gs $\alpha$ in the renal proximal tubule (4). As a result, the diagnosis of PHP1A is often delayed, especially in patients with non-specific features such as obesity or short stature $(2,4,5,6,7)$. Childhood obesity was proposed as an early clinical sign of PHP $1 \mathrm{~A}$ as it might develop in very early life and could even be recognized before any other endocrine disturbances $(2,5)$. Our patient developed obesity from the age of 2 years and later developed symptoms of PTH resistance at the age of 9.5 years. Therefore, PHP1A diagnosis should be suspected in children who present with isolated hyperthyrotropinemia or mild congenital primary hypothyroidism and obesity early in life to avoid delayed diagnosis.

Gonadotropin resistance has been described in patients with PHP1A $(2,3,7)$. Delayed or incomplete puberty with elevated gonadotropin levels could thus be one of the 
PHP1A phenotypes. Symptomatic gonadotropin resistance has been detected more commonly in female PHP1A patients while elevation of gonadotropin levels without symptoms has rarely been reported in male PHP1 A patients $(2,3,8,9,10,11,12)$. Interestingly, our patient developed CPP instead, which is exceptionally rare among patients with PHP1A. To the best of our knowledge, there have only been two male PHP patients with CPP reported in the English literature (Table 1) $(13,14)$. Both of them and our patient had CPP at the presentation of PHP. One patient had clinical features of PHP1A and the diagnosis was confirmed by demonstrating a heterozygous frameshift variant in exon 7 of the GNAS gene (13). The other patient manifested PTH resistance in the absence of AHO phenotypes; PHP type $1 \mathrm{~B}$, the disease associated with epigenetic alterations at the GNAS locus, was likely the diagnosis (14). Hence, CPP could manifest regardless of the type of genetic defect underlying PHP. The mechanism of CPP remains unclear. In parallel with PHP patients who developed CPP, CPP was previously described in girls with Turner syndrome who commonly have ovarian failure $(16,17)$. Functioning ovarian tissue, which is infrequently present in girls with Turner syndrome and could be responsive to FSH surge preceding the ovarian failure, may be the cause of CPP found in Turner syndrome patients (16). Similarly, CPP in boys with PHP1A might be mediated by testicular androgen production in response to elevated gonadotropin levels during childhood before developing partial gonadotropin resistance later in life. Nevertheless, coincidental idiopathic CPP in our patient cannot be excluded. Idiopathic CPP in girls is indeed much more common than in boys (18). Interestingly, to the best of our knowledge, CPP in girls with PHP1A has not been reported. This might be due to a gender discordance of resistance to gonadotropins in patients with PHP1A. Inactivating mutation of Gs $\alpha$-coupled receptor along hypothalamic-pituitary-gonadal axis that causes CPP has not been identified. Indeed, Gso-coupled receptor has not been shown to be a part of the neuroendocrine regulators of male puberty (19).

\section{Conclusion}

In conclusion, isolated hyperthyrotropinemia presenting with congenital hypothyroidism may be the first manifestation of PHP1A. Apart from the typical gonadotropin resistance, CPP may also be found in male PHP1A patients.

\section{Acknowledgment}

The authors thank Stephen Pinder, a medical education/ English specialist for proofreading of the manuscript.

\section{Ethics}

Informed Consent: Informed assent and consent were obtained from the patient and his parents, respectively.

Peer-review: Externally peer-reviewed.

\section{Authorship Contributions}

Surgical and Medical Practices: Somboon Wankanit, Pat Mahachoklertwattana, Preamrudee Poomthavorn, Concept: Somboon Wankanit, Pat Mahachoklertwattana, Preamrudee Poomthavorn, Design: Somboon Wankanit, Pat Mahachoklertwattana, Preamrudee Poomthavorn, Data Collection or Processing: Somboon Wankanit, Pat Mahachoklertwattana, Preamrudee Poomthavorn, Analysis or Interpretation: Somboon Wankanit, Pat Mahachoklertwattana, Thipwimol Tim-Aroon, Kinnaree Sorapipatcharoen, Preamrudee Poomthavorn, Literature Search: Somboon Wankanit, Pat Mahachoklertwattana, Thipwimol Tim-Aroon, Kinnaree Sorapipatcharoen, Preamrudee Poomthavorn, Writing: Somboon Wankanit, Pat Mahachoklertwattana, Thipwimol Tim-Aroon, Kinnaree Sorapipatcharoen, Preamrudee Poomthavorn.

Financial Disclosure: The authors declared that this study received no financial support.

\section{References}

1. Mantovani G, Bastepe M, Monk D, de Sanctis L, Thiele S, Ahmed SF, Bufo R, Choplin T, De Filippo G, Devernois G, Eggermann T, Elli FM, Garcia Ramirez A, Germain-Lee EL, Groussin L, Hamdy NAT, Hanna P, Hiort O, Jüppner H, Kamenický P, Knight N, Le Norcy E, Lecumberri B, Levine MA, Mäkitie O, Martin R, Martos-Moreno GÁ, Minagawa M, Murray P, Pereda A, Pignolo R, Rejnmark L, Rodado R, Rothenbuhler A, Saraff V, Shoemaker AH, Shore EM, Silve C, Turan S, Woods P, Zillikens MC, Perez de Nanclares G, Linglart A. Recommendations for Diagnosis and Treatment of Pseudohypoparathyroidism and Related Disorders: An Updated Practical Tool for Physicians and Patients. Horm Res Paediatr 2020;93:182-196. Epub 2020 Aug 5

2. Mantovani G, Bastepe M, Monk D, de Sanctis L, Thiele S, Usardi A, Ahmed SF, Bufo R, Choplin T, De Filippo G, Devernois G, Eggermann T, Elli FM, Freson K, García Ramirez A, Germain-Lee EL, Groussin L, Hamdy N, Hanna P, Hiort O, Jüppner H, Kamenický P, Knight N, Kottler ML, Le Norcy E, Lecumberri B, Levine MA, Mäkitie O, Martin R, MartosMoreno GÁ, Minagawa M, Murray P, Pereda A, Pignolo R, Rejnmark L, Rodado R, Rothenbuhler A, Saraff V, Shoemaker AH, Shore EM, Silve C, Turan S, Woods P, Zillikens MC, Perez de Nanclares G, Linglart A. Diagnosis and management of pseudohypoparathyroidism and related disorders: first international Consensus Statement. Nat Rev Endocrinol 2018;14:476-500

3. Mantovani G. Clinical review: Pseudohypoparathyroidism: diagnosis and treatment. J Clin Endocrinol Metab 2011;96:3020-3030. Epub 2011 Aug 3

4. Turan S, Fernandez-Rebollo E, Aydin C, Zoto T, Reyes M, Bounoutas G, Chen M, Weinstein LS, Erben RG, Marshansky V, Bastepe M. Postnatal establishment of allelic Gas silencing as a plausible explanation for delayed onset of parathyroid hormone resistance owing to heterozygous Gas disruption. J Bone Miner Res 2014;29:749-760. 
5. Kayemba-Kay's S, Tripon C, Heron A, Hindmarsh P. Pseudohypoparathyroidism Type 1 A-Subclinical Hypothyroidism and Rapid Weight Gain as Early Clinical Signs: A Clinical Review of 10 Cases. J Clin Res Pediatr Endocrinol 2016;8:432-438. Epub 2016 Jul 20

6. Picard C, Decrequy A, Guenet D, Bursztejn AC, Toledano D, Richard N, Kottler ML. Diagnosis and management of congenital hypothyroidism associated with pseudohypoparathyroidism. Horm Res Paediatr 2015;83:111-117. Epub 2015 Jan 9

7. Linglart A, Levine MA, Jüppner $H$. Pseudohypoparathyroidism. Endocrinol Metab Clin North Am 2018;47:865-888. Epub 2018 Oct 12

8. Linglart A, Carel JC, Garabédian M, Lé T, Mallet E, Kottler ML. GNAS1 lesions in pseudohypoparathyroidism Ia and Ic: genotype phenotype relationship and evidence of the maternal transmission of the hormonal resistance. J Clin Endocrinol Metab 2002;87:189-197.

9. Long XD, Xiong J, Mo ZH, Dong CS, Jin P. Identification of a novel GNAS mutation in a case of pseudohypoparathyroidism type $1 \mathrm{~A}$ with normocalcemia. BMC Med Genet 2018;19:132.

10. Wu YL, Hwang DY, Hsiao HP, Ting WH, Huang CY, Tsai WY, Chen HC, Chao MC, Lo FS, Tsai JD, Yang S, Shih SL, Lin SP, Lin CL, Lee YJ. Mutations in pseudohypoparathyroidism 1a and pseudopseudohypoparathyroidism in ethnic Chinese. PLoS One 2014;9:e90640.

11. Sano S, Nakamura A, Matsubara K, Nagasaki K, Fukami M, Kagami M, Ogata T. (Epi)genotype-Phenotype Analysis in 69 Japanese Patients With Pseudohypoparathyroidism Type I. J Endocr Soc 2018;2:9-23.

12. Lee YS, Kim HK, Kim HR, Lee JY, Choi JW, Bae EJ, Oh PS, Park WI, $\mathrm{Ki}$ CS, Lee HJ. Identification of a novel mutation in a patient with pseudohypoparathyroidism type Ia. Korean J Pediatr 201 4;57:240-244. Epub 2014 May 31
13. Kagami R, Sato T, Ishii $T$, Araki E, Yamashita $Y$, Shibata H, Ishihara J, Hasegawa T. Central precocious puberty in a boy with pseudohypoparathyroidism type Ia due to a novel GNAS mutation. Clin Pediatr Endocrinol 2020;29:89-90. Epub 2020 Apr 16

14. Rossodivita A, Miceli Sopo S, D’Alessio E, Valentini P. Gonadotropin-dependent sexual precocity in a boy affected by pseudohypoparathyroidism. J Pediatr Endocrinol Metab 2000;13(Suppl 1):845-847.

15. Richards S, Aziz N, Bale S, Bick D, Das S, Gastier-Foster J, Grody WW, Hegde M, Lyon E, Spector E, Voelkerding K, Rehm HL; ACMG Laboratory Quality Assurance Committee. Standards and guidelines for the interpretation of sequence variants: a joint consensus recommendation of the American College of Medical Genetics and Genomics and the Association for Molecular Pathology. Genet Med 2015;17:405-424. Epub 2015 Mar 5

16. Sabin MA, Zacharin MR. Precocious puberty in Turner syndrome. J Paediatr Child Health 2007;43:776-778.

17. Improda N, Rezzuto M, Alfano S, Parenti G, Vajro P, Pignata C, Salerno M. Precocious puberty in Turner Syndrome: report of a case and review of the literature. Ital J Pediatr 2012;38:54.

18. Latronico AC, Brito VN, Carel JC. Causes, diagnosis, and treatment of central precocious puberty. Lancet Diabetes Endocrinol 2016;4:265274. Epub 2016 Feb 4

19. Avendaño MS, Vazquez MJ, Tena-Sempere M. Disentangling puberty: novel neuroendocrine pathways and mechanisms for the control of mammalian puberty. Hum Reprod Update 2017;23:737-763. 